LAW, ETHICS, AND MEDICINE

\title{
The new Italian law on assisted reproduction technology (Law 40/2004)
}

\author{
V Fineschi, M Neri, E Turillazzi
}

J Med Ethics 2005;31:536-539. doi: 10.1136/jme.2004.010231

The Italian parliament passed the law on assisted reproduction after a heated debate. The promulgation of this law (Law $40 / 2004$ ) is the end point of a long and troubled journey that has seen many bills come and go, all of which have failed. The law consists of a whole set of regulations that will have a great impact on health and on society in general. The law is against many of the technical practices of assisted reproduction; several such practices are banned. This paper outlines ethical and medicolegal issues arising in connection with the law. The law states that no more than three embryos must be created at any one time and all the embryos created must be transferred together even if the couple does not need all the embryos. Embryo cryopreservation is also forbidden, as is assisted reproductive technology (ART), which uses a third party in any way, and the screening of embryos for genetic defects.

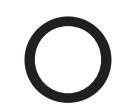
n the 10th of February 2004, the Italian parliament finally promulgated a law, law 40/2004, setting out the rules for assisted reproductive technology (ART). All of the many previous attempts to introduce this legislation had failed. The regulations embodied in the law will have far reaching effects on health and on society itself in Italy. Recent data show that in Italy one couple in five cannot have children; one child in every 100 is a test tube baby; the average wait in the private sector for assisted reproduction technology is four months; the average wait in the public health system is six months; the average cost for an intervention is 3000-10 000 euros; the number of children born via assisted reproduction techniques each year is 6000; 5022 couples own frozen embryos; the number of preserved embryos is 24276 , and there are 323 centres specialising in assisted reproduction. According to an estimate of the World Health Organization (WHO) in developed countries, the percentage of sterile couples-the potential users of ARTvaries between $15 \%$ and $20 \%$. As far as assisted reproduction is concerned, in Italy there has been, for too many years already, a climate of pointless antagonism between those who consider it necessary for there to be rigorous and detailed legislative control and those who regard only minimal legal intervention necessary. Those who favour the latter course believe that such legislation as is necessary should aim merely to regulate what are already widespread and accepted practices in contemporary society, by dealing with any minor difficulties that have arisen from these practices, and plugging any gaps in the law. Instead of providing general directions for the conduct of ART, the Italian legislature has preferred to lay down a very restrictive text, characterised by a very long and detailed list of restrictions. The law prohibits cryopreservation of embryos, limiting to three the number of embryos that can be implanted in each single cycle; it forbids assisted reproduction using a third party in any way, as well as access to reproductive technology for couples who carry genetic diseases with risk of transmission. Moreover, the law prohibits scientific research on embryos. Therefore what we now have in Italy is a set of regulations that places strict and remarkable limits on the use of assisted reproduction techniques.

Even before its final promulgation, the law gave rise to heated discussion, not only at the political level but also at a national $^{1}$ and international ${ }^{2-5}$ scientific level. The scientific debate aimed to point out the extreme rigidity and restrictiveness of the limits imposed by the proposed new rules.

\section{THE PRINCIPLES OF THE NEW LAW ON ART}

The law undoubtedly represents a step forward in the bewildering ART scene in Italy. It has become apparent over recent years, that some sort of regulation of ART was necessary because it was being used without any control. In recent years, Italian jurisprudence has often been involved in cases of disownment of paternity following $\mathrm{ART}^{6}$; children born by insemination after the death of the father, and surrogate motherhood. ${ }^{8}$ Because of such very serious cases, the intervention of the legislature to protect the child born through the use of ART, by establishing his legal status (art 8 ), and prohibiting the disownment of paternity and the mother's anonymity (art 9), seems entirely appropriate.

In the wake of the law, guidelines have been issued by a specifically nominated ministerial committee (art 7). The guidelines, drawn up in July 2004, are strictly binding on all authorised centres, and have to be updated at least every three years, in line with scientific progress. The aim of the ministerial guidelines is to give technical instructions to the medical staff of every centre authorised to conduct ART. Therefore they cover only a few points of the law, such as couples' ability to access reproductive technologies [for the couples] (art 4); the procedures governing informed consent (art 6); the characteristics of couples wishing to access ART (art 12), and, finally, experimentation on human embryos (art 13).

It appears to the authors that the regulation of the centres authorised to apply ART must be welcome because the regulations define their technical and scientific requirements; define the characteristics of the staff; set out the criteria for permitting and revoking the authorisation to conduct ART, and lay down the criteria that will govern how the law is observed. Moreover, a national register has been established (art 11) by the Istituto Superiore di Sanità (National Institute of Health). This register will record the names of the centres authorised to conduct ART, the number of embryos created, and the number of children born following the application of. This register provides proof that there is already an awareness

Abbreviations: ART, assisted reproduction technology; CECOS, Centro Studio e Conservazione Ovociti e Sperma Umani; PGD, preimplantation genetic diagnosis; WHO, World Health Organization 
of the need for strict control of health issues and for constant quality checks on both the operators' professionalism and the adequacy of the equipment and applied technologies of the authorised centres.

The law begins with the statement that recourse to ART is allowed only in order to assist the solution of reproductive problems arising as a result of human sterility or infertility, so as to guarantee the rights of all the involved subjects, including the conceptus (art 1). After this initial statement, the law lists a long series of prohibitions. In particular, recourse to assistance from a third party is expressly forbidden. The law confirms that couples who carry genetic diseases with risk of transmission, may not access ART. In any case such couples would not be able to seek such help because the law makes it mandatory to implant all embryos at the same time without preimplantation genetic diagnosis (PGD).

If some juridical and doctrinaire attempts to outline an absolute right to procreation, including even medically assisted procreation, are not convincing, another right is certainly well defined, namely the right to health. Therapies for sterility and infertility surely fall within this area of the right to health. ${ }^{9}$

In other words, sterility and infertility-an inability to procreate-are negative health conditions. Therefore the problem of ART must be dealt with from the point of view of protection of health. From this perspective ART must involve medical procedures and must be motivated by therapeutic needs; health concerns, such as the infertility of the woman or the couple, are required to constitute legitimate access. This is in accordance with the notion of disease within the broad concept of health, which is accepted not only at an international level, but also by the Italian law on the reform of the health system. Such a concept of health clearly includes the condition under examination-namely sterility. ${ }^{10}$

If this is the main idea behind the law and if ART, motivated by strictly therapeutic needs (sterility or infertility), implies medical procedures directed toward the protection of the health of the woman and of the couple (sterile or infertile), then it is not clear why the law has allowed only reproductive techniques that exclude the use of third parties. This means that couples whose infertility/sterility problems cannot be solved using their own gametes, and couples who cannot bring pregnancy to a conclusion because of the risk of transmitting a genetic disease, are excluded from help. The inconsistency is even more obvious if one considers how the Italian law 194/78, which regulates voluntary pregnancy interruption, provides (among the conditions that can determine that serious danger for the mother's psychological and physical health required by the law to allow pregnancy interruption) for "expectations of anomalies or malformations of the child about to be born" (art 4). Thus, in the case of foreseeable fetus malformation, termination may be allowed to protect the mother's psychophysical health. Even where there is the same need to protect health, however, couples are forbidden to resort to ART using gametes or assistance from a third party. Also, couples carrying genetic anomalies with risk of transmission, for whom there is a very high risk of conceiving a malformed fetus, are forbidden to use preimplantation genetic diagnosis in order to avoid having a child with a genetic disease. ${ }^{11}$

It is not clear how one can justify, beyond the blind acceptance of a preconceived and rigid ideological approach, having legitimated and allowed the use of reproductive technologies only for some sterile couples-namely, those whose sterility problems can be solved using the couple's own gametes. It is almost as if only such cases of sterility/ infertility are to be granted the dignity of being called disease, as if only this form of inability to procreate is worthy of ART. What about couples in which the man suffers from azoospermia? And couples carrying genetic diseases? And HIV discordant couples (male partner HIV positive, female partner HIV negative) wishing to have their own children? ${ }^{12} 13$

If assisted reproductive technologies are indeed first of all, and indisputably, medical therapeutic acts directed at safeguarding the health of sterile couples, one wonders how it can be right that the legislature has in fact excluded from such constitutionally protected safeguarding so many sterile women and couples. This is of great relevance if one considers that about $20 \%$ of the 50000 Italian couples who turn to ART can only procreate or be given the chance to try to procreate using gametes from a third party, be that either by using a donor's semen and/or a donor's embryos.

The reasons for the dispute regarding ART using gametes from a third party arise from deep issues of an ethical juridical nature. ${ }^{14} 15$ Even disregarding practical and organisational problems connected with the cryopreservation of gametes-for example, to do with sperm banks and the selection of donors-ART using gametes from a third party raises delicate moral and ethical issues because of the entry of a third person unrelated to the couple-the donor of the gametes. Also, questions of a strictly juridical nature arise. It is enough to think of the dichotomy between the genetic father (the donor of the gametes) and the social father; of the question of the donor's anonymity, and of the already mentioned possibility that legal action aimed at the disavowing of paternity may be taken. Similar problems arise when reproduction requires the donation of oocytes. In this case we have the dichotomy between the genetic mother (the woman from whom the oocyte comes) and the social and pregnant mother (the woman who has the pregnancy and gives birth to the child).

Because of all these potential problems one would have hoped for state intervention, which while allowing recourse to ART involving third parties, would have laid down strict provisions regarding the organisation and regulation of centres, gamete banks and the selection of donors, and regulated all matters of a strictly juridical nature-for example, disavowing of paternity, donor anonymity, and surrogate motherhood. In respect of practices involving third parties, the authors had hoped that the legislature would intervene to impose mandatory conditions such as the selection of semen based on characteristics of a social, economic, and professional nature, or on the basis of gender, being illegal, and donation having to be made freely and not for financial recompense. The authors had also hoped the legislation would ensure the safety and quality of centres and sperm banks, and protect the legal status of children born by means of ART.

The Italian code of medical ethics (1998) dedicated one article to the problems surrounding assisted reproduction ${ }^{16}$ stated here. Faced with the persistent lack of legislation, it tried to supply precise and detailed instructions for medical doctors. The code itself underlined the need for a regulation of programmes for assistance in reproduction and provided a series of specific criteria that clinics offering such services should meet. In this field the legislature could have-and should have-taken action to make a real commitment to protect the personal rights of the woman, of the couple, and of the unborn child.

Article five establishes other subjective requirements of couples who can access ART: couples must be adults of different genders, married or living together, potentially fertile, and both living.

The law also establishes very precise limits to the doctor's autonomy regarding therapeutic choices in the matter of 
ART. In articlel4 the law goes as far as establishing the highest number of embryos to be used in one "only and simultaneous implant", forbidding, at the same time, the cryopreservation of embryos. The Italian legislature translated scientific knowledge into rigid and prescriptive codes without taking any account of the circumstances in which such knowledge is applied and without leaving any space for the operation of the doctor's discretionary powers, which are an essential cultural and technical characteristic of the doctor's work. Such interference on the part of the legislature in the strictly medical aspect of ART cannot but leave the authors greatly perplexed. We, the authors, believe that the entire medical profession must not remain indifferent to such legislative high handedness. What is striking and worrying in the law here, is the "dangerous" interference of the legislature in a matter that surely is not only technical and organisational, but which instead concerns the deepest essence of the medical profession itself, a complex mixture of scientific knowledge, moral values, and the autonomy of its decision making.

Instead of respecting medical professionalism, with regard to ART, the legislature did not hesitate to translate into prohibitions and unconditional limits what present medical science provides as merely technical indications or guidelines. Moreover, they are dealing with scientific data, the validity of which has given rise to an ongoing lively discussion ${ }^{17-22}$ : this debate itself goes to show just how complex the technical data are, and clearly demonstrates that they cannot and should not be translated into legal regulations. With respect to this, it is sufficient to remember that in the self regulation code of the Human Sperm and Oocyte Research and Conservation Centre (Centro Studio e Conservazione Ovociti e Sperma Umani or CECOS), elaborated by experts in the field, regarding the number of embryos to be transferred into the uterus (article13), it is literally stated: "The transfer of embryos into the uterus must be limited to a number compatible with that which the woman can bring to a conclusion with sufficient probabilities of success and with the lowest possible risk of multiple pregnancies". ${ }^{23}$ This leaves plenty of space for the doctor's discretionary power, for his experience, and for his knowledge. Furthermore, according to the Italian Society on Infertility and Sterility (Società Italiana Infertilità e Sterilità or SIFES) regulations, a maximum number of three embryos should be transferred to women under 35 years and a maximum number of four embryos to women over 35 years, with a variability due to the age of the woman (which is not considered by the law), while the supernumerary embryos should be frozen to be used again in subsequent transfers, so as to avoid, in case of failure of the first attempt, the woman having to submit again to ovarian hyperstimulation cycles.

Three points are not scientifically sound: ${ }^{2}$

- 1) the rigid prescription of the number of embryos to be transferred and the prohibition of cryopreservation of embryos;

- 2) the risks to the woman's health caused by the necessity of more cycles of ovarian hyperstimulation, and

- 3) the increase in the number of multiple pregnancies because of the required simultaneous implanting of three embryos.

To support these fundamental objections that the authors have raised to the law, it is appropriate to report some strictly technical data from CECOS that show how, when conducting in vitro fertilisation and embryo transfer, the number of attempts varies depending on the age of the woman.

At present the percentage of unfrozen embryos varies between $60 \%$ and $75 \%$, whereas the possibility of pregnancies after the transfer of embryos is about $10 \%$. The incidence of syndromes due to ovarian hyperstimulation, which is necessary with the so called major assisted reproduction techniques where a superovulation of varying degree is expected, are calculated to be around 23\%: $7.6 \%$ mild, $11.95 \%$ moderate, and $3.9 \%$ severe. $^{23}$

Moreover the authors can report that "the crucial point of the process is the possibility of choosing the embryos which morphologically present the best characteristics and to freeze the others. Working in this way, the percentage of clinical pregnancy is around $27-29 \%$ for each cycle of in vitro fertilisation, as it is reported by the American and European registers. To this percentage is added a further $15 \%$ in cases where a cycle of unfrozen embryos is carried out...It is clear that preventing the possibility of freezing embryos will mean a diminution in therapeutic successes of more than two thirds, going from about $30 \%$ of national average to less than $10 \% " .{ }^{23}$

The law 40/2004 denies this in a way that is almost beyond contradiction.

The technical data confirm the intrinsic problems and the great technical scientific commitment that is needed if ART is to be successful. However, the new Italian law, which is both presumptuous and ignores scientific evidence, ventures to regulate in an extraordinarily rigid way a subject that by its very nature cannot be regulated.

One cannot help but repeat the question asked by one of the first commentators ${ }^{2}$ on the law: "Will the first bioethical legislation be non-scientific"?

It is necessary to consider another aspect of the law, namely the one relating to the provisions of article 13, which forbids "any experimentation on any human embryo...the production of human embryos for research or experimentation purposes".

Even without wanting to discuss the merits of the subtle, ethical, and religious questions that are raised relative to the embryo's condition and status, it is important for medical ethicists to underline how the law, with a few concise peremptory words, seeks to "liquidate" one of the emerging questions in scientific research, without taking any account of the abundance of contributions that have been made to this debate, at the highest level, in Italy. Such an extensive and complex subject-it is sufficient to think of the different implications of the various research technologies: cloning; adult stem cells; fetal stem cells; embryonic stem cellsrequires an appropriately complex law. The lawfulness of research on stem cells taken from adult tissues or from the umbilical cord or from spontaneously or voluntarily aborted fetuses would not seem to raise insurmountable questions. Actually, the argument about research on embryonic stem cells appears much more charged with ethical tensions than with technical ones. Here a radical controversy exists, based on different ethical notions, philosophically and/or religiously founded, each legitimate in its own right. The Dulbecco Commission, instituted by the Italian minister of health in September 2000 in order to study the "use of stem cells for therapeutic purposes", stated in December 2000, in its concluding paper that: "it is a duty of our society to foster and to support, in the most appropriate ways, research on all the sources of stem cells mentioned in the concluding remarks in the scientific part of the present document...In any case, concerning derivation of stem cells from embryos, the Dulbecco Commission recommends that such derivation should be allowed only from supernumerary embryos". This provides a clear demonstration of the complexity of the subject, which requires an appropriately normative approach. In fact for some time, it has been pointed out that to discuss ART and embryonic stem cell research together, in a single law, as if they were one subject, is to commit a fundamental 
conceptual mistake. Their only shared aspect is the availability of embryos.

The law underlines the need for informed consent (article 6): both subjects must want to access ART; this must be expressed in writing, along with the signature of the doctor who is responsible for carrying out the procedure at the centre concerned. A period of no fewer than seven days must elapse between the expression of the wish to access ART and the application of the technique. The wish can be revoked by each subject until the time of the insemination of the oocyte. The doctor with responsibility for carrying out the procedure at the centre has a duty to inform the subjects about the medical aspects of the methodologies and also about the juridical aspects (arts 8 and 9).

Finally, the law (art 16) provides for the possibility of conscientious objection on the part of the health professionals, who are not obliged to take part in the procedures of ART. Accordingly, physicians who have such a conscientious objection must make an early declaration of this. In strict analogy with the Italian law, which regulates access to voluntary pregnancy interruption, conscientious objection exempts health staff from the execution of procedures and activities specifically and necessarily directed toward assisted reproduction, but not from assistance before and after the intervention.

\section{CONCLUSIONS}

The new Italian Law on ART opened a Pandora's box of ethical and technical issues that must be urgently addressed. The new law is not good news for the many infertile couples needing several of the new technologies to help them to conceive. $^{3}$

The actual Italian debate on assisted reproductive technology will tend to focus on how the law will work, as it seeks to operate in conformity with doctrinaire specifications. These specifications maintain that ethicists and physicians are obliged to respect the new law and that any borderline problems should be looked at in the light of how the new law can be improved. "Certainly very special ethics enterprises, as when the ethicists are asked to consider a problem without precedent—for example, reproductive technology or genome mapping-might require a more intense communication between balloon (ethical theory) and bike (practical judgment)" ${ }^{24}$

\section{Authors' affiliations}

V Fineschi, M Neri, E Turillazzi, Institute of Legal Medicine University of Foggia, Foggia, Italy
Correspondence to: Vittorio Fineschi, Institute of Legal Medicine, University of Foggia, Ospedali Riuniti, Via L Pinto, no 1, 71100 Foggia, Italy; vfinesc@tin.it

Received 2 August 2004

In revised form 25 September 2004

Accepted for publication 29 September 2004

\section{REFERENCES}

1 Flamigni C. Sulla legge "cattolica" per la fecondazione assistita in Italia. Bioetica 2003;4:733-51

2 Wray E, Incorvati G. Assisted reproduction in Italy. Bull Med Ethics 2002;180:21-2.

3 Clarke $\mathbf{H}$. Italy approves controversial legislation on fertility treatment. Lancet 2003;362:2076.

4 Anon. Strict law on IVF passed in Italy. Reprod Biomed Online 2004;8:147.

5 Turone F. Italy passes new law on assisted reproduction. BMJ 2004;328:9.

6 Turillazzi E, Frati P. Fecondazione artificiale e disconoscimento di paternità. Rivista Italiana di Medicina Legale 1999;4-5:1268-82.

7 Fineschi V, Frati P, Turillazzi E. Fecondazione assistita e codice deontologico: quale convivenza dopo l'ordinanza di Palermo? Rivista Italiana di Medicina Legale 1999;6:1676-98

8 Fineschi V, Frati P, Turillazzi E. L'ordinanza capitolina sul contratto di maternità surrogata: problematiche etico-deontologiche. Rivista Italiana di Medicina Legale 2000;2:594-615.

9 Lockwood GM. Pregnancy, autonomy, and paternalism. J Med Ethics 1999;25:537-40.

10 Mori M. La fecondazione artificiale. Bari: Laterza, 1995.

11 Cameron C, Williamson R. Is there an ethical difference between preimplantation genetic diagnosis and abortion? J Med Ethics 2003;29:90-2.

12 Baker HV, Mijch A, Garland S, et al. Use of assisted reproductive technology to reduce the risk of transmission of HIV in discordant couples wishing to have their own children where the male partner is seropositive with an undetectable viral load. J Med Ethics 2003;29:315-20.

13 Spriggs M, Charles T. Should HIV discordant couples have access to assisted reproductive technologies? J Med Ethics 2003;29:325-9.

14 Schenker JG. Ethical aspects of advanced reproductive technologies. Ann NY Acad Sci 2003;997:11-21.

15 Harris J. Assisted reproductive technological blunders (ARTBs). J Med Ethics 2003;29:205-6.

16 Fineschi V. Un codice deontologico europeo per il medico ltaliano. In: Barni M, eds. Bioetica, deontologia e diritto per un nuovo codice professionale del medico. Milan: Giuffrè, 1999.

17 Templeton A, Morris JK. Reducing the risk of multiple births by transfer of two embryos after in vitro fertilization. New Engl J Med 1998;339:573-7.

18 Fujii S, Fukui A, Yamaguchi E, et al. Reducing multiple pregnancies by restricting the number of embryos transferred to two at the first embryo transfer attempt. Hum Reprod 1998; 13:3550-4.

19 Matson PL, Browne J, Deakin R, et al. The transfer of two embryos instead of three to reduce the risk of multiple pregnancy: a retrospective analysis. J Assist Reprod Genet 1999;16:1-5.

20 Dean NL, Phillips SJ, Buckett WM, et al. Impact of reducing the number of embryos transferred from three to two in women under the age of 35 who produced three more high quality embryos. Fertil Steril 2000;74:820-3.

21 Kovacs G, MacLachlan V, Rombauts L, et al. Replacement of one selected embryo is just as successful as two embryo transfers, without the risk of twin pregnancy. Aust N Z J Obstet Gynaecol 2003;43:369-71.

22 Meden-Vrtovec H. Ovarian aging and infertility. Clin Exp Obstet Gynecol 2004;31:5-8.

23 Human Sperm and Oocyte Study and Conservation Centre. www.cecos. it (accessed 26 Jul 2004).

24 Jonsen AR. Of balloons and bicycles-or-the relationship between ethical theory and practical judgment. Hastings Cent Rep 1991;21:14-16. 